\title{
Atividade antimicrobiana in vitro do ácido acético e dos vinagres branco e tinto sobre bactérias hospitalares*
}

\author{
I wa Keiko Ainda U tyama ${ }^{1}$ \\ Denise de Andrade ${ }^{2}$ \\ Evandro Watanabe ${ }^{3}$ \\ Izabel Yoko I to ${ }^{4}$
}

\begin{abstract}
Resumo
0 ácido acético e o vinagretêm longa história e aplicabilidade humana, incluindo o tratamento de feridas. Este estudo tem como objetivo avaliar in vitro a atividade antimicrobiana do ácido acético e de vinagres sobre cepas hospitalares. A atividade antimicrobiana foi avaliada por meio daT écnica de D ifusão dePoço, sobre cepas deStaphylococcusaureus, Pseudomonas aerugi nosa eE scherichia coli . Assim, os vinagres branco etinto foram diluídos a 30,0; 25,0 e 10,0\% eo ácido acético a 1,0 e 0,7\%. Para análiseestatística, foi usado o teste de variância AN OVA-O N EWAY, seguido do teste de comparações múltiplas, com nível designificância a =5\% . No computo geral, o vinagrebranco etinto a 30,0\% edo ácido acético a 1,0 e 0,7\% mostraram atividade antimicrobiana sobre P seudomonase Escherichia. $\mathrm{N}$ a concentração de 25,0 e $10.0 \%$, houve crescimento tênue de al gumas cepas e nenhuma ação sobre Staphyl ococcusaureus. D iante do exposto, épossível considerar queexisterelação direta entrea concentração do agentequímico ea atividadeantimicrobiana.
\end{abstract}

Palavras-chave: Acido acético-Testes de sensi bilidade microbiana-Pseudomonas aeruginosa-Staphylococcus aureuEscherichia coli; VinagreTetes desensibilidademicrobiana-Pseudomonas aeruginosa-Staphylococcus aureu-Escherichia coli

\section{INTRODUÇÃO}

0 ácido acético ( $\mathrm{CH} 3-\mathrm{COOH})$, conhecido como vinagre, é resultante da fermentação (oxidação) do álcool etílico, por ação da bactéria Acetobacter aceti. Tem longa história e aplicabilidade humana, incluindo a culinária (condimento azedo). ${ }^{1}$ São destacadas suas propriedades nutritivas, organolépticas, sanitizantes e até medicinais. Assim, é difundido o seu uso no tratamento de feridas ou lesões (verruga, calosidade, impetigo, furúnculo, queimaduras, picada de inseto, dentre outras), pediculose, na endodontia, otite, em processos inflamatórios da boca e garganta, no diagnóstico de neoplasias do cérvix uterino, na desinfecção

\footnotetext{
* Parte da Dissertação de M estrado apresentada EM 2003 ao Programa de Pós-Graduação em Enfermagem Fundamental. Escola de Enfermagem - USP. Ribeirão Preto - SP

1 Professora M estre. D epartamento de Enfermagem da Universidade Estadual de Londrina - UEL. Londrina -SP

2 Professora D outora. Escola de Enfermagem - U SP. Ribeirão Preto - SP. O rientadora do Programa de Pós-Graduação em Enfermagem Fundamental. D epartamento de Enfermagem Geral e Especializada - USP. Ribeirão Preto - SP

3 Farmacêutico. D outorando. Faculdade de Ciências Farmacêuticas - USP. Ribeirão Preto - SP

4 Professora Titular. Faculdade de Ciências Farmacêuticas - USP. Ribeirão Preto - SP

Correspondência para / Correspondence to:

D enise de Andrade

Escola de Enfermagem. D epartamento de Enfermagem Geral e Especializada - U SP. Ribeirão Preto - SP

Av. Bandeirantes, $\mathrm{n} \cong 3900$

14.040-902 Ribeirão Preto - SP

Tel.: (16) 3602-3398 / 3602-3462

Fax.: (16) 3633-3271/36302561

E-mail: dandrade@eerp.usp.br
} 
de alguns artigos semi-críticos, dentre outras aplicabilidades. $2,3,4,5,6,7,8,9,10$

Todavia, sua aplicabilidade in vivo tem merecido cautela, considerando, especialmente, a possibilidade de toxicidade tecidual. $N$ esse sentido, alguns estudos a respeito da atividade antimicrobiana de vinagres comerciais têm sugerido diferentes concentrações de uso in vivo. 2, 11, 12, 13, 14 Assim, a aplicabilidade desses produtos tem exigido a realização de pesquisas que avaliam o seu uso, de maneira a viabilizar a segurança em termos de atividade antimicrobiana, com isenção de irritabilidade dos tecidos.

Frente ao exposto, objetiva-se avaliar in vitro a atividade antimicrobiana do ácido acético e do vinagre (branco e tinto) por meio do $M$ étodo de Difusão do Poço sobre cepas hospitalares (Staphylococcus aureus, P seudomonas aeruginosa e de Eschericia coli).

\section{MATERIAL E MÉTODO}

A avaliação da atividade antimicrobiana dos vinagres (Branco e Tinto), diluídos a 30 , 25 e $10 \%$ e do ácido acético, a 1,0 e 0,7\%, sobre $P$. aeruginosa, E. coli e $S$. aureus recém isoladas de pacientes hospitalizados, foi realizada pela técnica de difusão de Poço em camada dupla, conforme Groove e Randal. ${ }^{15} \mathrm{O}$ meio de cultura M ueller $\mathrm{H}$ inton ( $\mathrm{O}$ xoid) foi empregado para obtenção tanto da camada base, bem como, da camada seed. Os inóculos foram preparados segundo normas técnicas, ou seja, obtidos pela suspensão em solução fisiológica, correspondendo a 0,5 da escala de M cFarland.

Após a solidificação da camada de seed, os poços de $4,0 \mathrm{~mm}$ de diâmetro foram perfurados, em fluxo laminar. A seguir, 20,0 ul de cada diluição foram aplicadas com pipeta automática em cada poço (FIGURA 1).

D ecorrido o período de incubação, foi realizada a mensuração do diâmetro do halo de inibição, com auxílio de uma régua milimetrada.

0 método de avaliação da atividade antimicrobiana por meio das medidas dos diâmetros dos halos de inibição está demonstrado na Figura 2.

Para análise dos resultados, utilizou-se análise de variância AN OVA-ONEWAY,

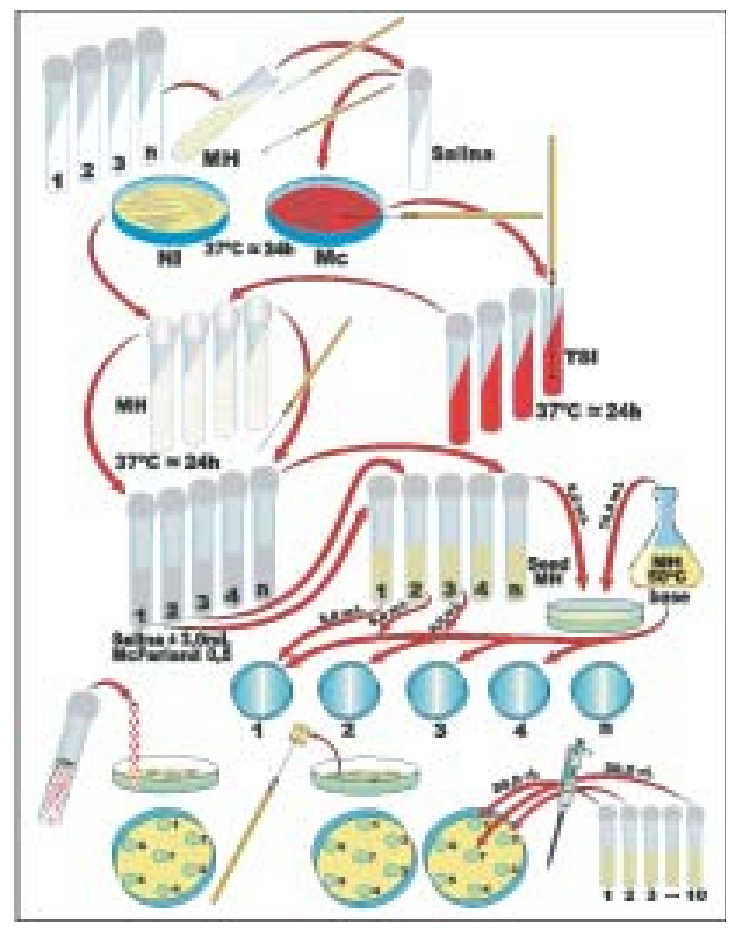

Figura 1- Fluxograma datécnica de difusão do poço

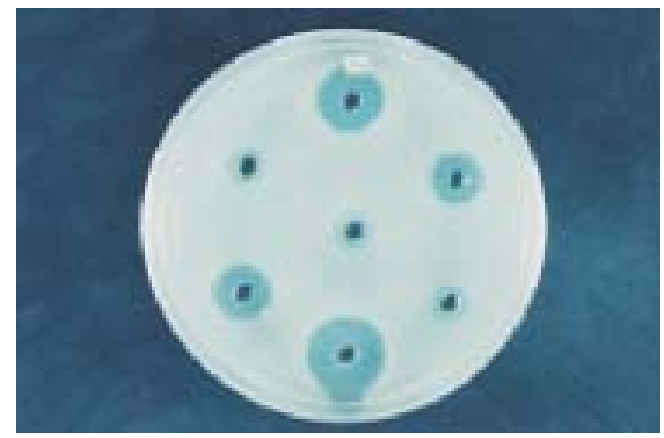

Figura2 - V ista panorâmica da ação antimicrobiana do ácido acético e vinagre por meio da técnica do Poço sobre as cepas Pseudomonasaeruginosa

seguida do teste de comparações múltiplas, com nível de significância de $a=5 \%,{ }^{16}$

Vale ressaltar que este estudo foi avaliado e aprovado pelo Comitê de Ética em Pesquisa (n०-7485/98).

\section{RESU LTAD O $S$}

No computo geral, foram verificados os resultados apresentados nas Tabelas 1 e 2 . 
Tabela 1 - D istribuição das médias dos diâmetros dos halos de inibição dos vinagres branco (VB) e tinto (VT) a 30,0, 25,0 e $10,0 \%$ sobre cepas de Pseudomonas aeruginosa ( $\mathrm{Pa}$ ), Staphylococcusaureus (Sa) e de Escherichia coli (Ec), pelo método de difusão do poço.

\begin{tabular}{l|c|c|c|c|c|c}
\hline Concentração & \multicolumn{5}{|c}{ Médias dos diâmetros dos halos de inibição Vinagres } \\
$\%$ & \multicolumn{5}{|c}{ Branco } \\
\hline & $\mathrm{Pa}$ & $\mathrm{Ec}$ & $\mathrm{Sa}$ & $\mathrm{Pa}$ & $\mathrm{Ec}$ & $\mathrm{Sa}$ \\
\hline 30,0 & 11,5 & 11,4 & 0 & 11,2 & 10,7 & 0 \\
\hline 25,0 & 10,6 & 10,2 & 0 & 10,4 & 9,9 & 0 \\
\hline 10,0 & 5,0 & 5,2 & 0 & 5,0 & 5,0 & 0 \\
\hline
\end{tabular}

Tabela 2-M édias dos diâmetros dos halos de inibição do ácido acético a 1,0e 0,7\% sobre Pseudomonas aeruginosa (Pa), Staphylococcusaureus (Sa) eEscherichia coli (Ec) pela difusão do poço.

\begin{tabular}{c|c|c|c}
\hline Concentração \% & \multicolumn{3}{|c}{ Médias dos halos de inibição } \\
& \multicolumn{3}{|c}{ Ácido acético } \\
& $\mathrm{Pa}$ & Ec & Sa \\
\hline 1,0 & 10,2 & 10,6 & 0 \\
\hline 0,7 & 6,5 & 7,7 & 0 \\
\hline
\end{tabular}

Segundo resultados das Tabelas 1 e 2, nas 22 cepas de Pseudomonas aeruginosa, 0 vinagre branco a $30,0 \%$ apresentou maior atividade antimicrobiana, com média do halo de inibição $(11,5 \mathrm{~mm})$, seguido de vinagre tinto a $30 \%$ $(11,2 \mathrm{~mm})$, vinagre branco a $25,0 \%(10,6 \mathrm{~mm})$, ácido acético a $1,0 \%(10,2 \mathrm{~mm})$, vinagre tinto a $25,0 \%(9,9 \mathrm{~mm})$, ácido acético a $0,7 \%$ $(6,5 \mathrm{~mm})$, vinagre branco e tinto a $10,0 \%$ $(5,0 \mathrm{~mm})$. Não foi encontrada diferença estatisticamente significante $(p>0,05)$ entre os resultados da ação antimicrobiana (médias das medidas dos halos) para as cepas do vinagre branco e tinto na concentração a 30,0 e 25,0\% e para o ácido acético a 1,0\%. Porém as soluções de vinagre e ácido acético mencionadas obtiveram valores mais elevados de significância $(p \varangle 0,05)$ que 0 ácido acético a 0,7\%, 0 vinagre branco e o tinto a $10,0 \%$.

Em síntese, 0 ácido acético a 0,7\% é mais eficaz que o vinagre, branco e tinto a $10,0 \%$, e, por sua vez, entre eles não há diferença significativa $(p<0,05)$. 0 vinagre branco e tinto 30,0 e $25,0 \%$ e ácido acético a $1,0 \%$, estatisticamente não mostraram diferença significativa quanto à ação antimicrobiana sobre as cepas de Pseudomonas aeruginosa, porém as soluções de vinagre e ácido acético mencionadas são mais eficazes que o ácido acético a 0,7\%, 0 vinagre branco e tinto a $10,0 \%(p<0.05)$. Em contrapartida, o ácido acético a $0,7 \%$ é mais eficaz que o vinagre, branco e tinto a $10,0 \%$, e, por sua vez, entre eles, não há diferenças significativas.

Q uanto à atividade antimicrobiana do vinagre branco a 30,0 e 25,0\% e o ácido acético a 1,0\%, sobre 21 cepas de Escherichia coli, constatamos que não há diferença estatisticamente significante, porém são mais eficazes que o vinagre branco e tinto a $10,0 \%$ eácido acético a $0,7 \%(p<0,05)$.

Em síntese, o estudo in vitro do ácido acético a 1,0 e 0,7\% pelo método de difusão de o poço mostrou atividade antimicrobiana significativa sobre Pseudomonas aeruginosa e Escherichia coli e nenhuma ação sobre Staphylococcus aureus.

\section{DISCUSSÃO}

D e um modo geral, é possível considerar que existe relação direta da concentração dos produtos químicos (vinagres branco e tinto e ácido acético) com a atividade antimicrobiana. $0 \mathrm{~s}$ vinagres branco e tinto inibiram todas as cepas de P.aeruginosa nas concentrações de 1,5 e a $2,0 \%$, respectivamente. $0 \mathrm{~s}$ resultados obtidos levam-nos a concluir que 0 Staphylococcus aureus é resistente à ação do vinagre e do ácido acético. Em adição, a investigação de Rund ${ }^{17}$ também evidenciou que Staphylococcusaureussobreviveram após 24 horas de exposição ao vinagre em uma concentração de $0,25 \%$.

M erece destaque o estudo de Araújo e colaboradores ${ }^{12}$, que constataram que as cepas de Pseudomonas spp., incluindo a cepa padrão (ATCC 27853), foram inibidas in vitro pelo ácido acético nas concentrações de $2,0 \%, 1,0 \%$, $0,5 \%$ e $0,25 \%$. 
M olineros e colaboradores mostraram que 0 ácido acético a 1,0\% não apresentou atividade antimicrobiana sobre cepas de E. coli, Pseudomonas e Proteus. ${ }^{5}$ Ainda os estudos parecem apontar que a ação antimicrobiana depende da concentração de hidrogênio que produzem. Complementam alguns estudiosos que o conservante adicionado pelos fabricantes (pirossulfito de potássio) induz a formação de sais com o ácido, diminuindo, dessa forma, a quantidade de íons livres de hidrogênio. 5, 6

$0 \mathrm{pH}$ representa uma outra variável a ser considerada, e é destacado que o pH mínimo de crescimento para a maior parte das bactérias oscila entre 4 a 4,4 e o ótimo está entre 6,5 a 7,5. ${ }^{14}$

Em estudo in vitro com cepas de Staphylococcus aureus, utilizando-se duas substâncias, ácido acético e ácido clorídrico, sob mesmas condições de $\mathrm{pH}$, verificou-se que 0 ácido acético foi mais efetivo, supondo-se que essa ação, até certo ponto, deva ser do próprio produto e não ao baixo $\mathrm{pH} .{ }^{11,17}$

Constatou-se que a concentração igual ou inferior a $0,7 \%$, especificamente a $0,5 \%$, pode atuar como agente desinfetante frente às cepas de E. coli, Staphylococcus aureus e Pseudomonas aeruginosa, presente nos materiais semi-críticos. 6

Finalmente, questiona-se: Qual é o mecanismo de ação antimicrobiana do vinagre e do ácido acético sobre as cepas analisadas? D entre as possíveis explicações tem-se as apresentadas a seguir.

Considerando que, na composição química do vinagre e do ácido acético, encontrase o álcool, então se conclui que quanto maior a concentração de álcool dos respectivos produtos, maior será a atividade antimicrobiana.

Especificamente em relação à composição química dos produtos analisados, conforme a descrição do fabricante, há 90,0\% de álcool e $10,0 \%$ de vinho no vinagre branco. Ao contrário, o vinagre tinto apresenta $90,0 \%$ de vinho e 10,0\% de álcool, e, portanto, com ação antimicrobiana inferior. Esse dado pode justificar a atividade antimicrobiana do vinagre branco em relação ao tinto. Assim, a presença de álcool nas soluções de vinagre pode estar interferindo na ação antimicrobiana.

Pode-se especular também que a ineficácia do vinagre e do ácido acético nas concentrações testadas esteja relacionada à constituição química da parede celular.

0 principal componente da estrutura da parede celular é um peptidoglicano (mureína), um polímero misto de açúcares hexose (N acetilglicosamina e ácido $\mathrm{N}$-acetilmuramínico) e aminoácidos. $\mathrm{N}$ as bactérias $\mathrm{G}$ ram-positivas, no caso Staphylococcus sp (cocos Grampositivo), o peptidoglicano forma uma camada espessa (20-80nm), tornando a parede mais rígida, suportando maior pressão que as bactérias Gram-negativas. 0 álcool não solubiliza proteína e açúcar. N as bactérias $\mathrm{G}$ ramnegativas, Pseudomonas aeruginosa e E. coli (bacilo Gram-negativo aeróbio o primeiro e anaeróbio o segundo), a camada de peptidoglicano é delgada (5 a 10nm), mas apresenta uma porção externa de lipopolis-sacarídeo e lipoproteínas, proteína, fosfolipídeo e ainda é dotada de porina, canal para transporte de nutriente e subprodutos.

A parede celular da cepa Gram-negativa tem uma camada fina complexa e não suporta tanta pressão quanto as Gram-positiva, mas é dissolvida na presença de álcool. E, como o vinagre e o ácido contêm álcool, pode ser essa a fundamentação da atuação do álcool nos componentes da parede celular. Pouco se sabe sobre o mecanismo de ação antimicrobiana do ácido e do vinagre. No entanto, suspeita-se que a quantidade de proteína e (ou) lipídio existente na parede celular possa interferir na referida atividade antimicrobiana.

\section{CONSIDERAÇÕES FINAIS}

D iante das pesquisas acerca da atividade antimicrobiana do vinagre e do ácido acético, é passível de constatação a importância de estudos que permitam a utilização segura in vivo, ou seja, que as soluções não sejam tóxicas e mantenham ação antimicrobiana de amplo espectro. 
Embora, as substâncias analisadas tenham relativa toxicidade, por outro lado possuem vantagens, pois são biodegradáveis, têm baixo custo ealta disponibilidade, o que justifica emanar esforços na realização de estudos pré clínicos em modelo animal, com a finalidade de viabilizar futuramente a sua aplicabilidade in vivo, especialmente em feridas infectadas.

Ainda que não tenha sido a preocupação, neste momento, a de correlacionar os dados deste estudo com o uso in vivo, é importante atentar que os respectivos produtos têm sido utilizados como agentes antimicrobianos no tratamento de feridas, e algumas vezes, em concentrações elevadas, o que, conseqüen- temente, poderá, além de causar danos aos tecidos, também dificultar o processo de cicatrização.

Vale ressaltar que o mecanismo de ação do produto é fortemente influenciado na presença de um ou vários componentes ativos, culminando ou não com compatibilidades físico-químicas que reduzem ou aumentam a atividade antimicrobiana.

A nosso ver, é premente despertar nos profissionais da saúde a consciência críticareflexiva em relação à utilização das evidências científicas em prol da qualidade da assistência à saúde.

\title{
Antimicrobial activity in vitro of acetic acid and white vinegar and red on bacteria'shospital
}

\begin{abstract}
A cetic acid and vinegar have a long history and human applicability including the clinical treatment of wounds. O bjective: to evaluate in vitro the acid antimicrobial activity of acetic and the vinegar by means of the technique of diffusion of well of Staphylococcusaureus, P seudomonasaeruginosa and Escherichia coli. The study was applied to assessment of the antimicrobial activity of acetic acid (M erck) a 1,0 e 0,7\% and white vinegar and red at 30,0; 25,0 e 10,0\%. The strains of Pseudomonas aeruginosa, E. coli e Staphylococcus aureus have been isolated of hospitalized patients. For analysis statistics the test of variance AN OVA - ONEWAY followed of the test of multiple comparisons was used; with level of significance = $5 \%$. In general the white and red vinegars $30.0 \%$ and of acetic acid 1,0 and $0.7 \%$ had shown significant to antimicrobial activity on Pseudomonas aeruginosa and Escherichia coli. In the concentration of 25,0 and $10.0 \%$ there was tenuous growth of some and no action on Staphylococcus aureus. It is possible to consider that there is direct relation of the chemical agent concentration with the antimicrobial activity or inhibition of bacteria.
\end{abstract}

Keywords. Acetic acid- M icrobial sen sitivity tests-P seudomonasaeruginosa-Staphyl ococcusaureus-E scherichia coli; Vinegar- M icrobial sensitivity tests-Pseudomonas aeruginosa-Staphylococcus aureus-Escherichia coli.

\section{REFERÊNCIAS}

1 FLORENTINO, E.R. et al. Avaliação das principais características de vinagres comerciais. Hig. Aliment., São Paulo, v.18, n.119, p.36-39, abr. 2004.

2 PHILLIPS, I. et al. Acetic acid in the treatment of superficial wounds infected by
Pseudomonas aeruginosa. Lancet, London, v.6, p.11-12, 1968.

3 AM INIFARSHIDMEHR, N. The management of chronic suppurative otitis media with acid media solutions. Am. J. O tol., 1996; $17: 24-25$. 
4 ANDREW S, K.; M OW LAVI, A.; M ILNER, S.M. The treatment of alkaline burns of the skin by neutralization. Plastic Reconstr. Surg., $\mathrm{H}$ agerstown, v.111, n.6, p.1918-1921, M ay 2003.

5 MOLINEROS, J.R. et al. El empleo del ácido acético como antiséptico: un enfoque racional. R. Colomb. O rtop. Traumatol., Bogotá, v.52, n.2, p.117-124, feb. 1991.

6 BENASSATTI, H.E.; MARFIL, L.M.; OCCHIONERO, M. Ácido acético: su capacidad desinfectante. Acta Bioquím. Clin. Latinoam., La Plata, v.28, n.3, p.411-419, 1994.

7 EST RELA, C.R. et al. Substancia ESP: opção na terapêutica endodôntica. JBE: J. Bras. Endod., v.5, n.19, p.273-279, 2004.

8 SAN KARAN ARAYANAN, R. et al. Visual inspection with acetic acid in the early detection of cervical cancer and precursors. Int. J. C ancer, N ew York, v.80, n.1, p.161-163, Jan. 1999.

9 SLOSS, J.M.; CUMBERLAND, N.; MILNER, S.M. Acetic acid used for the elimination of Pseudomonas aeruginosa from burn and soft tissue wounds. J.R Army Med Corps, London, v.139, n.2, p.49-51, June 1993.

10 GALVANE, J.0 ; ROTELI-M ARTIN S, C.M.; TADINI, V. Achados da inspeção visual com ácido acético para rastreamento de câncer do colo uterino. DST: J. Bras. Doenças Sex.
Transm., Rio de Janeiro, v.14, n.1, p.43-45, 2002.

11 AKIYAM A, $\mathrm{H}$. et al. Effects of acetic acid on biofilms formed by Staphylococcus aureus. Arch. D ermatol. Res., Berlin, 291, n.10, p.570573, 0 ct. 1999.

12 ARAÚjO, G.F. et al. Eficácia in vitro do ácido acético em Pseudomonas spp. Acta Cir. Bras., São Paulo, v.10, p.201-203, 1995.

$13 \mathrm{~N}$ agoba, B.S. et al. Acetic acid treatment of Pseudomonal postoperative wound infection. J. H osp. Infect., London, v.36, n.3, p.243-244, July 1997.

14 MAZZO LA, P.G .; MARTIN S, A.M.S.; PEN N A, T.C.V. Determination of decimal reduction time ( $D$-value) of chemical agents used in hospital disinfection. Braz. J. Microbiol., São Paulo, v.34, p.33-34, nov. 2003. Suppl.1.

15 GROVE, D.C.; RANDAL, W.A. Assay methods of antibiotics: a laboratory manual. New York: Medical Encyclopedia, 1955. (Antibiotics monographs, 2)

16 TUKEY, L.D.; FISHER, G.V.B. Bioestatistics: a methodology for the health sciences. N ew York: Wiley, 1993.

17 RUND, C.R. Alternative topical therapies for wound care. In: KRASNER, D.; KANE, $D$. Chronic wound care: a clinical source book for healthcare professionals. $2^{\text {nd }}$. ed. Wayne: H ealth M anagement Publ., 1997.

\section{Agradecimentos}

A M araísa Palhão Verri, farmacêutica e técnica do Laboratório de M icrobiologia da Faculdade de Ciências Farmacêuticas de Ribeirão Preto-U SP, pela colaboração no processamento das técnicas microbiológicas. 